\title{
Ovarian Mucinous Adenocarcinofibroma
}

National Cancer Institute

\section{Source}

National Cancer Institute. Ovarian Mucinous Adenocarcinofibroma. NCI Thesaurus. Code C40034.

A malignant neoplasm of the ovary with an invasive epithelial component and a fibrotic stroma. The epithelial component is characterized by the presence of malignant epithelial cells with intracytoplasmic mucin. Cystic spaces are also present which contain mucoid material. 